\title{
Governance e reforma do Estado: o paradigma agente x principal
}

\section{Introdução}

A discussão contemporânea sobre o Estado tem se centrado na questão dos requisitos societais, organizacionais e políticos que permitem que o Estado seja eficiente (Kaufrman, 1996). Mais do que isso, esta discussão tem privilegiado também a capacidade governativa em sentido amplo, e que se refere não só ao Estado, mas também aos requisitos do bom governo. O presente texto tem dois objetivos principais. Em primeiro lugar, discutir o conceito de governance e sua relevância para a análise contemporânea da reforma do Estado. A discussão recente em torno do conceito de governance ultrapassa o marco do modus operandi das políticas e engloba questões mais amplas, relativas a padrões de coordenação e cooperação entre atores sociais. No entanto, ela se distingue das questões de governabilidade. Em segundo lugar, introduzir e discutir o paradigma "agente principal" no debate sobre governance. Pela importância que esse paradigma vem assumindo nas análises em torno da questão, na agenda de pesquisas, parece oportuno promover discussões em torno do tema. O texto apresenta também, em caráter exploratório, uma análise de um componente importante no quadro da reforma - a descentralização - com recurso a alguns conceitos desse paradigma.

\section{Governance: as bases institucionais da cooperação}

O conceito de governance tem adquirido grande importância no debate contemporâneo em torno da reforma do Estado. O conceito está ancorado numa problemática mais ampla sobre o papel das instituições e do impacto da qualidade da matriz institucional de uma sociedade -

Marcus André Melo é Professor de Ciência Politica da Universidade Federal de Pernambuco 
no desenvolvimento (MARCH \& OLSEN, 1989; NORTH, 1990). As instituições podem ser entendidas como "regras formais, procedimentos de observância dessas regras e práticas regulares operativas, que estruturam o relacionamento entre indivíduos e as várias unidades do sistema político e econômico" (HALL, 1992, p. 96). Ou como "regras formais, constrangimentos informais e formas de se assegurar seu cumprimento" (NORTH, 1990, p. 386). Para Bates, as instituições representam "investimentos". As sociedades criam instituições da mesma forma que firmas têm set up costs ao fazerem investimentos; seus custos são amortizados ao longo do tempo, na forma de um ambiente estável para transações (TSEBELIS, 1990). No contexto de informação incompleta e de incerteza, os indivíduos têm altos custos para obter informação relevante sobre "o que" ele ou "com quem" ele está transacionando. Numa sociedade na qual as instituições estão insuficientemente desenvolvidas e consolidadas, tais custos são proibitivos e inibem um número potencialmente gigantesco de transações. A existência de instituições permite uma economia coletiva de custos de transação, permitindo ganhos para toda a sociedade. Na ausência de incerteza e oportunismo, as instituições poderiam ser substituidas por promessas. Sob incerteza e oportunismo, as promessas dão lugar a contratos cuja validade e cumprimento (enforcement) são assegurados por regras.

As instituições - ou pelo menos as boas instituições - servem para superar dilemas de ação coletiva e situações conhecidas na literatura sobre escolha racional como "dilemas do prisioneiro" (SHEPSLE, 1989; LANE, 1993; GEDDES, 1994). Esse conceito descreve situações em que uma melhoria das posições dos membros de uma coletividade deixa de ser realizada porque os indivíduos têm desincentivos para as promover unilateralmente. Nessas situações, o comportamento não-cooperativo deixa de produzir uma melhoria global na situação dos individuos. Como assinala North:

"Soluções bem-sucedidas [desses dilemas] têm implicado na criação de instituições que, nos termos da teoria dos jogos, aumentam os beneficios de soluções cooperativas ou aumentam os custos da defecção, e que, em termos de análise de custos de transação, reduzem custos de transação e produção em cada troca, de forma que os ganhos de troca' tornam-se realizáveis. Qualquer que seja a abordagem, a chave são as instituições" (NORTH, 1990).

$\mathrm{Na}$ formulação do Banco Mundial, "governance é definida como a maneira pela qual o poder é exercido na administração dos recursos econômicos e sociais tendo em vista o desenvolvimento" (World Bank, 1992). Com efeito, podemos distinguir este conceito do de governabilidade, que descreve "as condições sistêmicas de exercício do poder em 
um sistema político". Enquanto a governabilidade se refere às condições do exercício da autoridade política, governance qualifica o modo de uso dessa autoridade (MELo, 1995).

A capacidade de governance implica a capacidade governamental de criar e assegurar a prevalência - ou seja capacidade de enforcement de regras universalistas nas transações sociais, políticas sociais e econômicas, penalizando ou desincentivando o comportamento rent seeking, promovendo arranjos cooperativos e reduzindo os custos de transação. Do ponto de vista politico, governance implica também a capacidade das elites governamentais de resistência à captura por grupos de interesse (FrISCHSTAK, 1994) e a promoção da accountability (PZEWORSKI, 1995; DıNız, 1995). Como assinala um documento do Banco Mundial, "a accountability está no centro da boa governance e se refere a tornar os governos responsáveis por suas ações" (World Bank 1994, 12).

O conceito de governance também tem sido usado com referência a formas e mecanismos de coordenação e cooperação não necessariamente ancorados no uso da autoridade pública, como nos casos amplamente referidos pela literatura sobre processos de auto-regulação e "governo privado" (embora neste último o Estado esteja presente). Nesse sentido mais amplo, governance ou governance system é definido como a "totalidade de arranjos institucionais - incluindo regras e agentes que assegurem o cumprimento dessas regras - que coordenam e regulam transações dentro e fora dos limites de um sistema econômico" (HOLLINGSWORTH, SCHMITTER \& STREECK, 1993). Nesta perspectiva, a análise transcende o plano meramente institucional-governamental e inclui "mercados, redes sociais, hierarquias, e associações" como modos alternativos de governance. A descoberta recente de redes informais (de fornecedores, familias, gerentes) como uma variável fundamental na explicação do desempenho econômico aponta para as limitações do mercado enquanto modo de governance.

De forma geral, pode -se concluir com NORTH (1990) que o impacto da vida institucional sobre o desenvolvimento econômico é fundamental e se processa de forma incremental, permitindo um alargamento gradativo do horizonte temporal do cálculo econômico e das transações societais em geral.

"O crescimento econômico bem-sucedido é a história da evolução de instituições cada vez mais complexas, que tornam possível relações cooperativas de troca que se estendem por longo periodos de tempo entre individuos que não se conhecem. Credibilidade institucional significa que nós podemos ter confiança em resultados cada vez mais distantes do nosso conhecimento - um requisito para realizar o potencial da moderna tecnologia, a qual exige uma imensa especialização e divisão de trabalho." 
$O$ paradigma agente $\mathrm{x}$ principal: instituições como constrangimento ao comportamento oportunista

O neo-institucionalismo econômico tem se constituido na escola intelectual que recentemente tem trazido os aportes mais fecundos para a análise das instituições em geral e da burocracia, em particular (MOE, 1984). O neo-institucionalismo econômico desenvolveu instrumentos analíticos para a análise das transações sociais em situações de mercado e fora dele - como é o caso de contextos organizacionais e hierárquicos (sejam privados ou públicos). Nesse sentido, supera-se a dicotomia tradicional Estado x mercado e se desloca a análise para a estrutura de incentivos que produzem resultados racionais do ponto de vista coletivo. Como assinala Przeworski, "falar do mercado como um objeto de intervenção do Estado obscurece o ponto principal: o problema que encontramos não è a questão do mercado versus o Estado, mas dos mecanismos institucionais especificos que podem trazer incentivos e informação aos agentes econômicos privados, e ao Estado, que os leve a comportar-se de forma socialmente racional". (1992, p. 51). ${ }^{2}$

Ao romper metodologicamente com pressupostos do comportamento maximizador e adotar o conceito de racionalidade constrangida (bounded rationality), o neo-institucionalismo econômico pode explorar o impacto da incerteza nas transações sociais. Nesse quadro analítico adota-se um paradigma contratualista para examinar as instituições e a interação entre indivíduos ou grupo de individuos nessas instituições. As transações podem ser representadas como contratos entre duas partes. $\mathrm{O}$ neo-institucionalismo econômico desenvolveu-se inicialmente na área da teoria da firma e organização industrial, para se expandir nas áreas de economia do trabalho, teoria do mercado de capitais e teoria do desenvolvimento económico. A contribuição de Coase, na área da teoria da firma, na década de 30 , foi no sentido de mostrar como a firma existe como uma forma de economizar custos de transação. Nesse sentido, uma estrutura hierárquica (uma firma) emerge como uma forma de superar falhas de mercado e oportunismo nas relações de mercado. De forma semelhante, a integração vertical de firmas é um mecanismo para internalizar informações (sobre preços privados, mercados, e asset specificity) antes não disponiveis, o que tornava a firma vulnerável ao comportamento oportunista de fornecedores, e, ao mesmo tempo, substituir uma relação de mercado por uma relação de autoridade. ${ }^{3}$ A mudança nos direitos de propriedade que o take over permite, leva a superar aquilo que os neoinstitucionalistas denominam "falhas de organização".

Observa-se, assim, que questões organizacionais e institucionais 
— organização econômica, formas de propriedade, controle e oportunismo nas relações contratuais - que são desconsideradas na teoria neoclássica (que enfatiza em particular a tecnologia) adquirem grande centralidade na construção analítica (WILLIAMSON, 1985; WILLIAMSON, 1975).

No âmbito de relações hierárquicas, em organizações e burocracias, nas relações do mercado, ou ainda no quadro de instituições politicas, as transações sociais podem ser modeladas como envolvendo agente e principal. No âmbito de organizações e burocracias, o agente representa o empregado contratado pelo principal para realizar uma tarefa préespecificada. No âmbito do mercado, o fornecedor representa o agente que é contratado para produzir bens e serviços para uma empresa conforme estipulado por um contrato. No âmbito do sistema politico, os políticos recebem uma delegação do grupo de "cidadãos-principal" para agir em seu nome. No moderno mundo corporativo, em que há uma separação entre propriedade e controle gerencial, os acionistas representam o principal e os Executivos, os agentes. Em todas essas situações pode-se identificar uma situação ex-ante - pré-contrato ou delegação - e uma situação ex-post - pós-contrato ou delegação.

O conceito central para analisar a relação agente-principal é o conceito de oportunismo. O oportunismo descreve à discrepância entre o comportamento dos indivíduos ex-ante e ex-post uma situação contratual. Como os individuos e firmas têm asset specificity - uma dotação única e peculiar de fatores sobre a qual só eles têm informação completa - e ao mesmo tempo existe uma assimetria de informação entre agente e principal, surge espaço para o oportunismo. Como jả assinalado, na ausência de oportunismo, as instituições (contratos) poderiam ser substituidas por promessas, pois essas últimas seriam tão boas quanto os atos das pessoas. $\mathrm{Na}$ ausência de racionalidade constrangida, as atividades humanas assumiriam a forma de planejamento, uma vez que a vida sócioeconômica seria previsivel. Na ausência de asset specificity, a competição no mercado substituiria as instituições.

As situações de manifestação de oportunismo ex-post são descritas pelo conceito de moral hazard. O exemplo típico é a situação do seguro para automóvel, no qual o preço da apólice de seguro é calculado com base numa expectativa de que o comportamento do contratante em termos de aversão a risco se mantenha no mesmo nivel da situação précontratual. Uma vez realizada a transação, o seguro passa a representar um "risco moral" - um incentivo perverso - para que o indivíduo se exponha a riscos maiores do que usualmente se expunha na situação précontratual. Na mesma linha, a introdução, na década de 70 , de seguros de depósito para bancos comerciais criou uma situação de "risco moral" para os bancos, já que poderiam incorrer em operações de empréstimos e crédito arriscadas, sem ter o risco de perder clientes. O seguro passou 
a inibir o comportamento prudente por parte dos clientes na escolha de instituições financeiras.

A aplicabilidade do conceito é ampla, e ele pode descrever arranjos institucionais e práticas de governo. Tecnicamente, moral hazard se refere a situações em que há incentivos para que o custo marginal privado de uma ação se afaste do custo marginal social. Enquanto o conceito de moral hazard resulta da não-observabilidade do comportamento do agente numa situação pós-contratual, adverse selection resulta da nãoobservabilidade da informação, valores e objetivos que norteiam as decisões do agente. O processo de recrutamento de pessoal é exemplificativo. Nesse caso, o principal tenderá a atrair um grande número de candidatos não qualificados a um cargo, e terá dificuldade em distinguir o individuo qualificado daqueles que alegam oportunisticamente dispor das mesmas qualificações. Da mesma maneira, ainda, no caso de seguro, individuos com riscos (e custos) mais altos são os mais prováveis de contratar seguro para cobrir tais riscos. As empresas de seguro deparam-se, portanto, com um problema de seleção adversa quando lançam planos de saúde.

\section{Reforma do Estado e accountability}

Problemas agente-principal estão no centro da vida democrática de duas formas essenciais. ${ }^{4}$ Em primeiro lugar, na questão da representação política. A relação entre cidadãos e seus representantes pode ser representada como uma relação na qual os representantes são agentes dos cidadãos (principal). As várias formas institucionais de tomada de decisão coletiva (entre outras, plebiscito, referendum, câmaras legislativas) são soluções alternativas para resolver problemas de informação assimétrica e oportunismo. As formas de democracia direta buscam minimizar esses problemas, mas os custos de transação envolvidos para estender plebiscitos ao conjunto das decisões de governo seriam proibitivos. No processo eleitoral, os cidadãos deparam-se com problemas de adverse selection porque encontram grandes dificuldades em distinguir entre os candidatos que apresentam promessas de comportamento futuro.

Na situação pós-contratual — isto é, após as eleições — os eleitos deparam-se com o incentivo ao moral hazard e podem mudar seu comportamento, isto é, podem renegar as promessas de campanha (como amplamente confirmado pela história política). Como os agentes só dispõem de mecanismos muito débeis de controle, muitas reformas institucionais são propostas como forma de fortalecer tais mecanismos: diminuição do tempo de mandato, maior freqüência de eleições, revogabilidade de mandato em caso dos programas não serem implementados, etc. 
A qualidade da vida democrática e a eficiência de um sistema político dependem fundamentalmente de como esses problemas são minimizados (PrZEWORSKI, 1995).

A segunda forma pela qual problemas agente $\mathrm{x}$ principal adquirem grande centralidade no funcionamento do Estado moderno diz respeito à relação entre governantes e a burocracia - ou seja, como os governantes (incluindo o Executivo e o Legislativo) podem controlar a burocracia. Esse ponto é discutido na seção a seguir.

\section{Governantes e as reformas das burocracias}

O controle do Executivo sobre a burocracia assumiu historicamente três formas históricas. A primeira é o controle patrimonialista do acesso aos cargos públicos. O controle sobre a burocracia confundia-se com o próprio poder do governante, e determinava os traços gerais do padrão existente: formato personalista de recrutamento, inexistência de requisitos de escolaridade ou proficiência e instabilidade da burocracia enquanto estamento. Nesse quadro, os problemas agente-principal, no relacionamento entre o Executivo e a burocracia, eram minimizados (embora distorções de outra ordem, como ineficiência sistêmica, etc., abundassem). É nesse sentido que JOHNSOV \& LIBECAP (1994, p. 4) concluem, paradoxalmente, que "sob o sistema de patronagem havia accountability". 5

A segunda forma histórica é aquela na qual as burocracias se profissionalizam, adquirem autonomia, estabilidade e se tornam insuladas do proccsso político. A formação dessas burocracias resultou de um processo amplo de despatrimonialização do Estado e que equivale ao processo de construção de burocracias "weberianas". Com efeito, foi o paradigma weberiano que informou as reformas administrativas que foram implementadas em virtualmente todos os paises capitalistas avançados entre 1880 e 1930, às quais se seguiu uma segunda onda de reformas no pós-guerra. É nesse contexto de independentização de burocracias que surgem problemas agente-principal na relação entre governantes e a burocracia.

O modelo weberiano foi substituido por um paradigma "pós-burocrático" (BARZELAY, 1992) a partir da década de 70. Enquanto as reformas do início do século voltaram-se para a padronização de procedimentos burocráticos, instituição do sistema de mérito e racionalização do setor público, pela adoção de práticas standards e universais, a segunda onda de reformas voltou-se precisamente para a criação de padrões empresarialistas (entrepreneurialism), inovadores (e não rotineiros), customizados e flexíveis (e não padronizados). ${ }^{6}$

Essa estratégia reflete, entre outras coisas (preocupações com custos, etc.), uma necessidade de "politizar a burocracia" (no sentido amplo do termo), tornando-a mais accountable. Nesse sentido, inverte-se a 
equação histórica: a promoção da accountability, na primeira fase, era perseguida a partir da eliminação de personalismos de Executivos pouco democráticos e conseqüente viabilização do profissionalismo. Na terceira fase, a promoção da accoumtability, ao contrário, seria alcançada pela implementação de mecanismos que permitissem reverter o excesso de insulamento de burocracias e não produzissem resultados. Nesse sentido, a estratégia consistia em alinhar os interesses de burocracias não-eleitas (agentes) de representantes eleitos (no Parlamento e no Executivo).

\section{Paradigmas de reforma: desenhar incentivos ou profissionalizar}

Segundo Miller, a grande variedade de propostas de reorganização burocrática pode ser agrupada em dois tipos ideais, que correspondem a duas tradições disciplinares. A primeira delas é a tradição da administração pública. Nessa tradição, são enfatizados aspectos relativos à identidade, socialização, crenças e capacitação. Com relação aos gerentes enfatizam-se fatores como liderança e capacidade de formar esprit de corps e induzir dedicação e identificação com os objetivos da organização.

A segunda tradição corresponde à tradição disciplinar da economia. Nela enfatizam-se aspectos relativos à estrutura de incentivos com que se deparam os atores em uma organização burocrática. Os atores em uma estrutura burocrática são analisados, a partir da imagem do homo economicus, como individuos racionais maximizadores de seus interesses e utilidades. Nesse sentido, esses indivíduos são sensiveis a incentivos organizacionais, como promoção na carreira, estrutura de remuneração, entre outros fatores. O paradigma agente-principal inscreve-se nessa tradição disciplinar, embora recentemente grande ênfase analítica tem sido colocada, no sentido de se unificar parcialmente as duas tradições (Miller 1990).

\section{Reforma do Estado e descentralização: na trilha do paradigma}

A questão do trade off entre ef iciência e accountability tem ocupado um lugar importante nas discussões sobre reforma do Estado. Reformar o Estado consiste essencialmente numa tarefa de redesenho da estrutura de incentivos com que os atores se deparam, de forma a assegurar a prevalência de padrões de cooperação e de racionalidade coletiva sobre interesses setoriais. O desenho dessa estrutura de incentivos é tarefa complexa. O caso da descentralização fornece um exemplo rico para a análise da governance na esfera local (HALFANI, M., MCCARTNEY, PATRICIA \& Rodrigulz, 1993). Como discutido abaixo, de forma exploratória, 
a descentralização traz em seu bojo importantes problemas agente-principal, onde o nivel central representa o principal, e as unidades subnacionais, os agentes.

Recentemente, o conceito de descentralização tem sido desagregado em várias dimensões ou noções correlatas, tais como: desconcentração, delegação e devolução (BID, 1994). No sentido amplo, e que envolve as três dimensões, a devolução pode ser definida como a "transferência ao nível intergovernamental de poder decisório sobre as esferas financeira, administrativa e programática". Neste sentido, diferencia-se - e se amplia - o conceito de desconcentração, o qual descreve mecanismos de transferência de encargos e tarefas entre unidades administrativas ou políticas subnacionais; ou de delegação, quando apenas algum grau de poder decisório é transferido. Quando a descentralização ocorre no âmbito de empresas, ou entre empresas e setor público, verifica-se um processo de terceirização.

Entendida enquanto transferência de poder decisório a municípios ou entidades e órgãos locais, a descentralização expressa, por um lado, tendências democratizantes, participativas, e de responsabilização e, por outro, processos de modernização gerencial da gestão pública - nos quais apenas a questão da eficiência é considerada. Essas duas dimensões complementares estão presentes nos processos de descentralização, mas a importância relativa assumida por esses dois vetores depende da natureza da coalizão política que dả suporte às reformas.

As justificativas de ordem econômica para a descentralização estão relacionadas aos ganhos em termos de eficiência alocativa que ela permite. A descentralização intra-organizacional em agências ou setores permite ganhos, tais como: maior heterogeneidade e variabilidade na provisão de serviços, maiores possibilidades de geração de inovações e aprendizado organizacional devido à competição intra-organizacional entre unidades administrativas. Neste último caso, a descentralização seria um market ou competition surrogate - ou seja, criaria incentivos que promovem competição e eficiência alocativa (ISRAEL, 1989, p. 89107). $\wedge$ descentralização, no sentido amplo, permite o surgimento de mecanismos de controle sobre o governo que não estejam presentes no caso da descentralização intra-organizacional. A competição política funciona como um desses mecanismos de controle, além de promover local policy entrepreneurship.

As vantagens da devolução e da promoção da autonomia local, inclusive financeira, são apontadas pelo modelo do federalismo fiscal. Segundo este modelo normativo das fïnanças públicas, cada tipo de bem público deve ser provido pelo nivel de governo que tiver maior vantagem comparativa em responder à diversidade de preferências dos grupos da população. A provisão centralizada de um pacote uniforme de bens e ser- 
viços públicos para toda a população poderia levar a uma oferta inferior ou superior ao nivel Pareto-eficiente que expressasse as preferências dos consumidores.

Do ponto de vista do financiamento, a teoria do federalismo fiscal tem como pressuposto que os bens públicos têm incidência espacial delimitada, circunscrevendo clientelas territorialmente definidas. Assim, a segurança nacional tem impacto nacional, enquanto a iluminação pública tem impacto local. A incidência da taxação para o financiamento desses bens deveria corresponder ao impacto territorial dos beneficios proporcionados pela provisão dos bens (nos exemplos em pauta, incidência nacional e local, respectivamente). No limite, o beneficio marginal decorrente da provisão do bem deveria se igualar ao seu custo marginal. A teoria do federalismo fiscal, portanto, justifica a existência de um grande número de governos subnacionais de forma a expressar adequadamente a variedade de preferências por bens públicos. Uma estrutura governamental descentralizada minimizaria portanto os riscos de que os tipos ou quantum de bens públicos ofertados não correspondam às preferências dos cidadãos ou ainda de que os beneficios relativos a um grupo (jurisdição) sejam arcados por outro grupo (jurisdição).

Estes modelos teóricos oferecem uma justificativa conceitual e normativa para a superioridade alocativa de estruturas descentralizadas. $\mathrm{Na}$ seção que se segue, exploram-se os limites e constrangimentos à implantação de reformas descentralizantes como também os efeitos perversos que podem resultar de estratégias reformistas.

\section{Limites e possibilidades da descentralização}

Após uma década de experimentos descentralizadores em vários países e continentes, já é possivel realizar uma avaliação mais realista e sistemática da descentralização. A maioria das contribuições sobre a questão, no entanto, ainda tendem a enfatizar suas virtudes. Poucos trabalhos têm explorado os limites e efeitos não antecipados das estratégias descentralizantes. Contribuições recentes das agências multilaterais têm adotado um tom mais cauteloso e menos laudatório em relação à descentralização. Para o Banco Interamericano, em seu Relatório sobre o Progresso Sócio-Econômico na América Latina, "a questão central é, portanto, sob que condições a opção descentralizada acarreta uma melhoria na qualidade da governança e contribui para um gasto mais efetivo em bens públicos locais como educação e saúde" (IDB, 1995: 175-176).

Por sua vez, para o diretor de Assuntos Fiscais do FMI, Victor Tanzi, "a questão central da discussão não é refutar a conclusão de que a descentralização pode trazer beneficios mas identificar situações nas quais esta política pode não trazer os resultados esperados 'a menos que 
mudanças importantes sejam promovidas nas condições existentes"” (TANZl, 1995, p. 8, ênfase no original).

Esse tom menos laudatório encontra respaldo teórico em MoE (1984) que aponta os problemas agente-principal em iniciativas de descentralização intra-organizacional:

"Tarefas e poder de decisão são delegados às unidades de nivel inferior na expectativa de que elas usem seu conhecimento especializado e capacidades produtivas para contribuir para os objetivos da organização. Porém, inevitáveis assimetrias de informação levam a problemas de incentivo. Uma unidade de nivel mais alto requisitando inputs para uma de nivel inferior pagará o preço da adverse selection, uma vez que só essas últimas dipõem de informação sobre como esses inputs são criados, e usarão essa informação a seu favor. Da mesma forma, uma unidade superior, que tente aumentar a eficiência produtiva de uma unidade inferior, vai se deparar com problemas de moral hazard porque a informação sobre comportamento produtivo está assimetricamente distribuída em favor desse último" (MOE, 1984, p. 755).

O mesmo argumento é utilizado por HAGGARD (1995) com relação a iniciativas de descentralização das relações intergovernamentais:

"Os niveis mais altos da organização se deparam com problemas de adverse selection e moral hazard: os niveis mais baixos da organização detêm conhecimento sobre em que tipo de informação seus inputs estão baseados, e eles podem utilizar essa informação para obter vantagens, ao mesmo tempo que têm incentivos para fazer 'corpo mole', ou distorcer as políticas, sobretudo para beneficiar clientes locais em detrimento de objetivos programáticos de governo" (HaGGARD, 1995, p. 33).

Dentre os efeitos não antecipados e perversos da descentralização, pode-se destacar um conjunto de mazelas que foram identificadas não só em paises do terceiro mundo, mas tambèm no primeiro. Estes efeitos perversos são produzidos em virtude da ausência de certos pré-requisitos para a centralização e resultam de um conjunto de fatores discutidos abaixo:

a) A transferência de receitas públicas sem responsabilidades de geração de receitas, rompendo o vínculo entre o beneficio (representado pela disponibilidade de recursos para gasto) e o custo (o ônus político e administrativo de gerar receita), cria problemas de moral hazard. Recursos de transferências tipicamente tendem a ser menos monitorados por atores locais (principais) do que recursos resultantes da taxação a nivel local. Por outro lado, as transferências de recursos têm ocorrido antes 
que se fortaleça a capacidade fiscal local. As próprias transferências passam a se constituir em desincentivo ao esforço fiscal local (efeito referido na literatura americana como o "flypaper effect"). Ademais, os governos locais se mostraram incapazes de arcar com o ônus político de gerar receita fiscal (IDB 1995; TANZı 1995).

b) Indefinição e ambigüidade quanto à definição de competências entre esferas de governo pela generalização de competências concorrentes. Tal indefinição tende a gerar e potencializar problemas agente-principal encontrados em estruturas de governo: a existência de múltiplos principais. Como assinala MOE (1984, p. 768): "as agências públicas são 'agentes parciais' de vários 'principais do governo', sem estar sob a responsabilidade de ninguém em particular, e sem nenhum conhecimento comum de como a autoridade é legitimamente dividida entre principais que concorrem entre si”. Essa situação tem levado à inércia e paralisia institucional na medida em que os mecanismos de responsabilização se tornam inoperantes.

c) Burocracias locais de baixa qualificação. Na maioria dos países e especialmente na $\Lambda$ mérica Latina, existe um hiato muito largo entre a qualificação das burocracias centrais e as locais (provinciais e municipais) (HAGGiARI), 1995; TANZI, 1995). Da mesma forma, existe um contraste marcado entre a qualificação dos burocratas da área fazendária e de planejamento e os da área social. A transferência de funções e atribuições da esfera federal significou, em muitos casos, perda de eficiência gerencial (pela multiplicação de problemas de informação assimétrica). Os efeitos da descentralização são perversos na medida em que as burocracias locais não têm capacidade institucional de prover adequadamente bens e serviços sociais.

d) Perda de capacidade regulatória e de formulação de politicas por parte do governo central pelo desmonte de estruturas setoriais centralizadas e relativamente insuladas da competição politica. Tais estruturas constituem-se em loci de expertise e de memória técnica em politicas públicas e, dificilmente, são encontradas ou podem mesmo ser construidas a nivel local.

e) Descentralização fiscal com transferência de impostos importantes para o nível dos Estados e províncias, que minou a capacidade do governo central de levar a cabo políticas de estabilização e reformas fiscais. Incapacidade de ajuste fiscal a nível local (através de bancos controlados pelos governos locais), devido ao problema de moral hazard (bail out pelos bancos centrais) para a indisciplina fiscal ${ }^{7}$ (IDB 1995; AFONSO, 1995; TANZI, 1995).

f) Porosidade do governo local em relação a elites locais e provinciais, acarretando maior corrupção e clientelismo. O risco de captura do Estado por elites locais é também muito grande. Os atores centrais nos 
processos de responsabilização política - como a Imprensa, o Legislativo e o Judiciário - são mais efetivos e independentes a nivel nacional. A representação de minorias também ocorre de forma mais efetiva no plano nacional (sobretudo nos sistemas de voto proporcional).

g) Fragmentação institucional. Proliferação de municipalidades ou entes administrativos a nivel local. Esta tendência pode ser observada com grande força no Brasil contemporâneo.

\section{Conclusões}

O conceito de governance representa um instrumento analítico importante para o estudo da reforma do Estado. Várias questões relativas ao modus operandi das políticas públicas (formato institucional dos processos decisórios, a definição do mix público/privado nas políticas, a questão da participação e descentralização, dos mecanismos de financiamento das políticas e do escopo global de programas - focalizados versus universalistas) podem ser tratadas dentro de um quadro analitico comum, como também podem ser articuladas a questões mais amplas enfatizadas pelo neo-institucionalismo econômico, como a questão da matriz institucional geral da sociedade. O paradigma agente-principal permite um tratamento mais rigoroso e formal da governance e representa um avanço na compreensão de questões institucionais. A discussão exploratória da descentralização deixou entrever o potencial heuristico que a questão encerra. 
1 Os ganhos de troca (gains from trade) representam o aumento global de bem-estar resultante do intercâmbio mutuamente benéfico (ou troca econômica) entre dois parceiros com dotações de recursos diferenciados.

${ }^{2}$ As reformas econômicas inspiradas no repertório de políticas da agenda neoliberal têm exigido um estado intervencionista não apenas para introduzir mudanças (o que ć reconhecido por alguns defensores dessas reformas), mas para dar sustentabilidade ao funcionamento do próprio mercado.

${ }^{3}$ A literatura sobre a chamada "cspecialização flexivel" - estruturas horizontalizadas e $\mathrm{cm}$ rede de fornecedores e empresas pós-fordistas - típica da chamada terza ltalia, enfatiza como o "governo privado" dos interesses de membros de uma associação substitui, de forma mais eficiente, alternativas de mercado ao comportamento oportunista (ou seja, à informação assimétrica c racionalidade limitada dos agentes cconômicos), tais como a integração vertical de firmas ou ramos.

${ }^{4}$ PRZEWORSKI $(1995$, p. 8) argumenta que três classes de relações são essenciais: a relação entre o Estado e os agentes econômicos privados; a relação entre cidadãos e o Estado; c a relação entre agentes do Estado, $\mathrm{cm}$ particular entre os burocratas $\mathrm{e}$ os políticos. Sua tese central é que a eficiência de um sistema econômico depende do desenho dessas três relações agente-principal.

5 No caso brasileiro, essa assertiva parece surpreendente e totalmente implausivel, em virtude do fato de que a tarefa de despatrimonialização não se completou.

6 Paradoxalmente, a tarefa histórica $\mathrm{em}$ paises industrializados da periferia ć, portanto, a de simultaneamente completar a formação de burocracias weberianas e de promover flexibilidade para que se possa superar as conhecidas patologias institucionais do setor público $\mathrm{em}$ ambientes sistemicamente submetidos a mudanças rápidas.

${ }^{7}$ A prática tradicional do Banco Central no Brasil de socorrer bancos estaduais (é por extensão os tesouros estaduais) em situações falimentares representa outro exemplo de "risco moral". A situação falimentar desses bancos decorre, como amplamente analisado, do comportamento predatório e rent seeking de oligarquias $\mathrm{c}$ politicos locais, que os utilizam para a sustentação de suas alianças. A expectativa de socorro do Banco Central inibe a adoção de quaisquer medidas de contenção e racionalização de iniciativa dos governos estaduais. Os custos políticos de medidas de austeridade fiscal são transferidos para a esfera federal $\mathrm{c}$ socializados. Tais práticas constituem um incentivo ao comportamento expansionista, uma vez que os beneficios desse comportamento são captados por essas coalizões locais e os custos são externalizados e socializados.

\section{Referências bibliográficas}

BARZELAY, Michael. Braking Through Bureaucracy, University of California Press, 1992.

DiNIZ, Eli. "Governabilidade, Democracia e Reforma do Estado: os desafios da construção de uma nova ordem no Brasil dos anos 90." Dados, n. 3, p. 385-416, 1995."

Friscutak, Leila. Governance Capacily and Economic Reform in Developing Countries. World Bank Technical Paper Number 254, 1994.

Geddes, Barbara. Politician's Dilemma: Building State Capacity in Latin America. Berkeley: University of California Press, 1995.

HagGaRD, Stefan. "The Reform of the State in Latin America", paper prepared for the 
Annual Bank Conference on Development in Latin America and the Caribbean. Rio de Janeiro, 12-13 junho, 1995.

Halfani, M.; McCartney. Patricia \& Rodriguez, A. "Towards an Understanding of Governance: The emergence of an Idea and its implications for Urban Research in Developing Countries." Mimco, Ford Foundation/GURI project, 1993.

Hollingsworth, J. R; SCHmitter, Philippe \& Streeck, W. (eds.). "Preface." Comparing Capitalist Economies: Variations in the Governance of Sectors. Oxford University Press, 1993.

HOLLIngsworth, J. R. and BOYER, Robert. "Contemporary Capitalism, The embeddness of Institutions." Mimeo, 1991.

Hall, Peter. "The Movement from Keynesianism to monetarism: institutional analysis and British Economic policies in the 1970s." Steinmo, Sven; THelen, Kathlene e LONGSTRETH, Frank (eds.). Structuring Politics, Historical Institutionalism in Comparative Analysis. Cambridge: University Press, p. 90-113, 1992.

IDB - Interamerican Development Bank (1994) "Fiscal Decentralization: The Search for Equity and Efficiency". Economic and Social Progress in Latin America. Report, 1994.

ISRAEL, Arturo. Institutional Development. World Bank/Johns Hopkins University Press, 1989.

Jounson, Ronald N. \& Libecap, Gary D. The Federal Civil Service and the Problem of Bureaucracy: The Economics and Politics of Institutional Change. The University of Chicago, 1994.

Kauffman, Robert. "The Politics of State reform: A review of Theoretical approaches." Rutgers University. Mimco, 1996.

LANE, Jan-Erik. The Public Sector: concepts, models and approaches. Sage, 1993.

LEVI, Margareth. "A Logic of Institutional Change." CooK, K. S. \& LEVI, M. (orgs.) The Limits of Rationality. Thic University of Chicago Press, p. 402-417, 1990.

MARCH, J. $\mathrm{e}$ OLSEN, J. Rediscovering Institutions: the organizational basis of politics. The Frec Press, 1989.

MELo, Marcus André. "Ingovernabilidade: desagregando o argumento." VALLADARES, Licia \& Coelho, Magda (orgs.). Governabilidade e Pobreza no Brasil. Rio de Janeiro: Civilização Brasileira, 1995.

Miller, Gary. "Managerial dillemas: Political lcadership in Hicrarchics." CoOK, K. S. \& LEVI, M. (orgs.). The Limits of Rationality. The University of Chicago Press, p. 324$348,1990$.

MOE, Terry M. "The New Economics of Organization." American Journal of Political Science, 28, 739-777, 1984.

NORTH, Douglas. Institutions, Institutional change and Economic Performance. Cambridge University Press, 1990.

PrZEWORSKI, Adam. "The Neolibcral Fallacy." The Journal of Democracy, vol. 3, n. 2, 1992.

PrZEWORSKI, Adam. "Reforming the State: Political Accountability and Economic Intervention." Mimeo, New York University, 1995.

Putnam, R. Making Democracy Work. Cambridge University Press, 1993.

SHEPSLE, Kenneth. "Studying Institutions: some lessons from the rational choice approach." Journal of Theoretical Politics, vol. I, n. 2, 131-147, 1989.

Stiglitz, J. "Principal and Agents." Eatwell, J. et al. (orgs.). The New Palgrave Dictionary of Economics. Macmillan, 1987.

TANZI, Vito. "Fiscal Federalism and Decentralization: A review of some efficiency and macrocconomic aspects." Annual Bank Conference on Development Economics. Washington, May 1-2, 1995.

Willitamson, Oliver. The Economic Institutions of Capitalism. The Free Press, 1981.

Williamson, Oliver. Markets and Hierarchies. The Free Press, 1975.

World Bank. Governance and Development, 1992.

World Bank. Governance: the Wolrd Bank Experience, 1994. 
Resumo

Resúmen

Abstract

\section{Governance e reforma do Estado: o paradigma agente x principal \\ Marcus André Melo}

O presente artigo discute de forma exploratória a questão da reforma do Estado com referência a dois desenvolvimentos teóricos que estão no centro do debate da questão. $O$ primeiro diz respeito à discussão sobre o conceito de governance. Argumenta-se que o conceito é distinto do de governabilidade e identificam-se duas formas de se entender a governance: como uso da autoridade pública c como regulamentação das relações entre agentes públicos e privados $\mathrm{e}$ entre agentes privados entre si. Apresenta, também, conceitos recentes desenvolvidos pelo neo-institucionalismo econômico, em particular no âmbito do paradigma agente-principal, explorando sua aplicabilidade para a análise do processo de descentralizaçào.

\section{Governance y reforma del Estado: e! paradigma agente x principal \\ Marcus André Melo}

El presente articulo discute de modo exploratório la cuestión de la reforma del Estado con referencia a dos visiones conceptuales que se hallan en el seno del debate teórico acerca de la cuestión. el primero dice respecto a la discusión del concepto de governance. Se plantea que el concepto es distinto del de gubernabilidad, y se identifican dos formas de comprender la governance: como uso de la autoridad pública y como regulación de las relaciones entre agentes públicos e privados y entre los agentes privados. El texto también presenta conceptos recientes, desarrollados por el nocinstitucionalismo económico, en particular, en el marco del paradigma agente-principal, explotando su aplicabilidad para el análisis del proccso de descentralización.

\section{Governance and State reform: the principal $x$ agent paradigm \\ Murcus André Melo}

This paper contributes to recent debates about the reform of de State concerning to two conceptual developments of these debates. The first is these developments is the involving notion of governance. A distinction is made, on the one hand, between the definition of governance as the manner in which state power is used and as forms of regulation and co-operation among private agents and between private agents and the state. In addition, the paper provides an introduction to central concepts and developments in the new institutional cconomics - in particular the principal-agent paradigm. The last section of the paper explores tentatively the application of some others concepts to processes of decentralisation. 